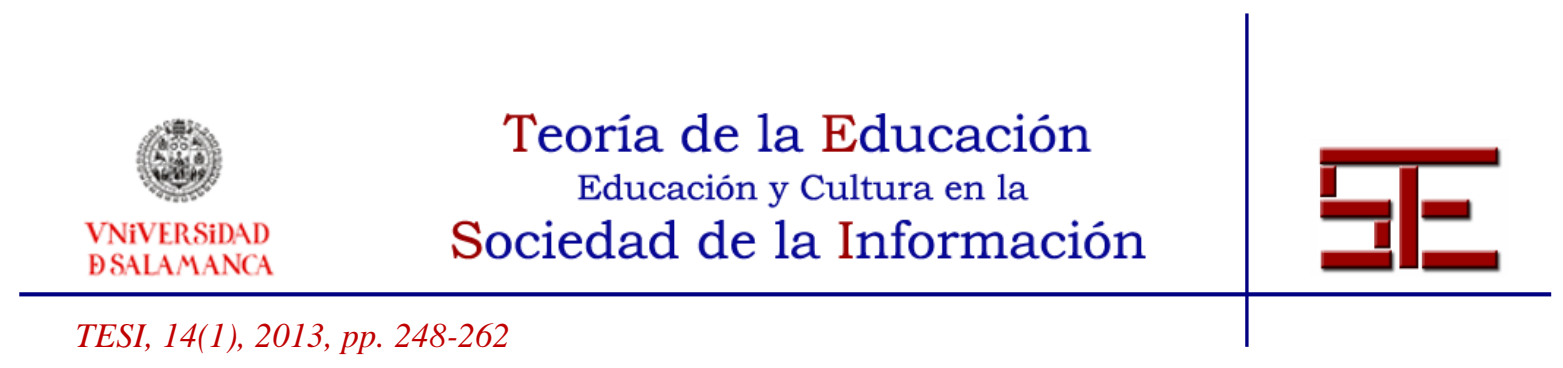

\title{
EL LUGAR DE LA AUTONOMÍA EN LA PEDAGOGÍA Y LA EDUCACIÓN POSTMODERNAS
}

Resumen: En esta comunicación pretendemos abordar el lugar que puede ocupar la autonomía ante la realidad educativa postmoderna. La autonomía ha sido, en la modernidad, un argumento central tanto en las teorías como en las prácticas educativas. Sin embargo, el actual contexto de postmodernidad epistemológica y de liquidez sociológica dibuja probablemente un momento de transición donde los conocimientos y los valores, como también las metodologías y las teorías que abogan por o se fundamentan en la autonomía del sujeto, están viendo cuestionada su legitimidad. La educación postmoderna, aquella que no admite la universalidad de verdades, valores ni prácticas, y que promueve unos vínculos sociales cada vez más líquidos y descomprometidos, se encuentra en contradicción con toda una suerte de elementos pedagógicos que, hasta hace bien poco, naturalizábamos y dábamos por supuestos. ¿Es la idea de autonomía en educación uno de los elementos que nos deberíamos replantear? Este trabajo pretende fundamentar esta pregunta y ensayar algunas posibles vías para intentar responderla.

Palabras clave: Autonomía; postmodernidad; teorías educativas; filosofía de la educación; valores sociales; relaciones humanas.

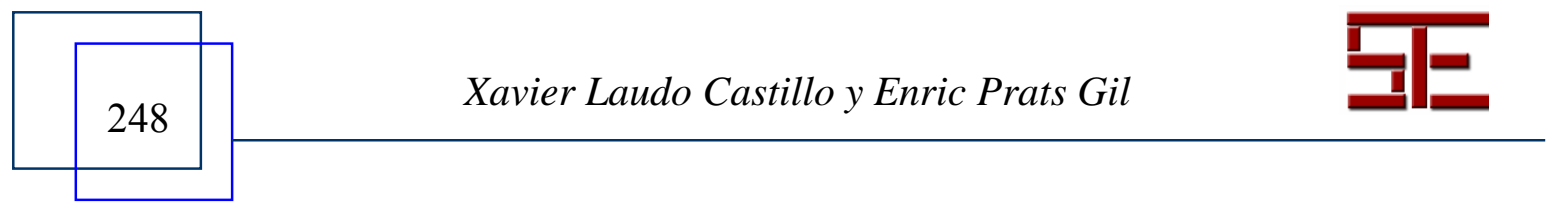




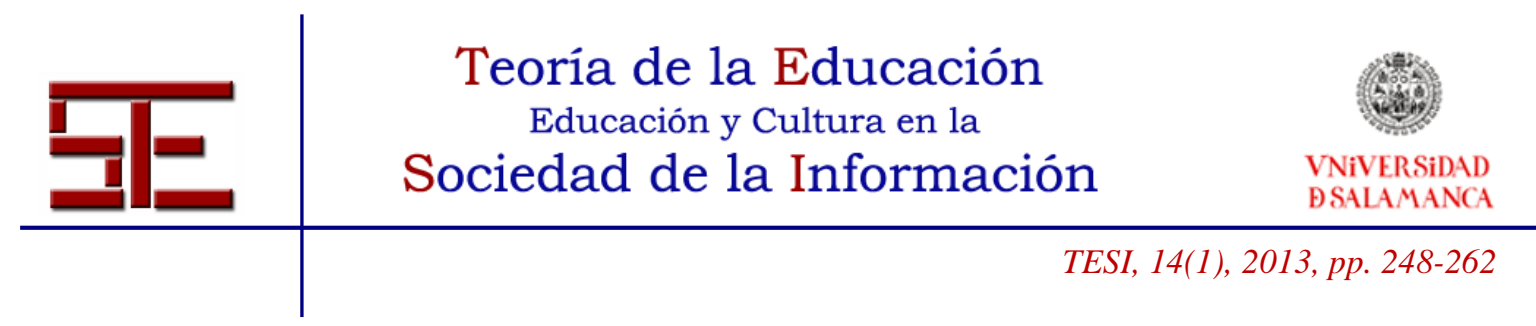

\section{THE PLACE OF AUTONOMY IN POSTMODERN PEDAGOGY AND EDUCATION}

Abstract: In this paper we intend to deal with that can occupy the place of autonomy to the postmodern educational reality. Autonomy has been, in Modernity, a central argument in both theory and educational practices. However, the current context of epistemological postmodernity and sociological liquidity draws probably a moment of transition where the knowledge and values, as well as the methodologies and theories that advocate for or are based on the autonomy of the subject, are being questioned its legitimacy. Postmodern education, one which does not allow the universality of truths, values and practices, and promotes social bonds more and more fluids and disengaged, is in contradiction with a whole lot of educational elements that, until recently, we naturalized and took for granted. Is the idea of autonomy in education one of the elements that we should rethink? This paper aims to substantiate this question and try out some possible ways to try to answer it.

Keywords: Autonomy; postmodernism; educational theories; educational Philosophy; social values; human relations.

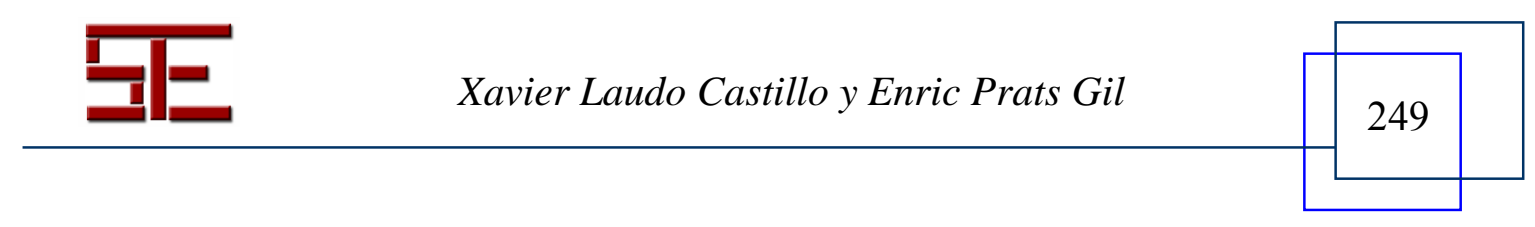




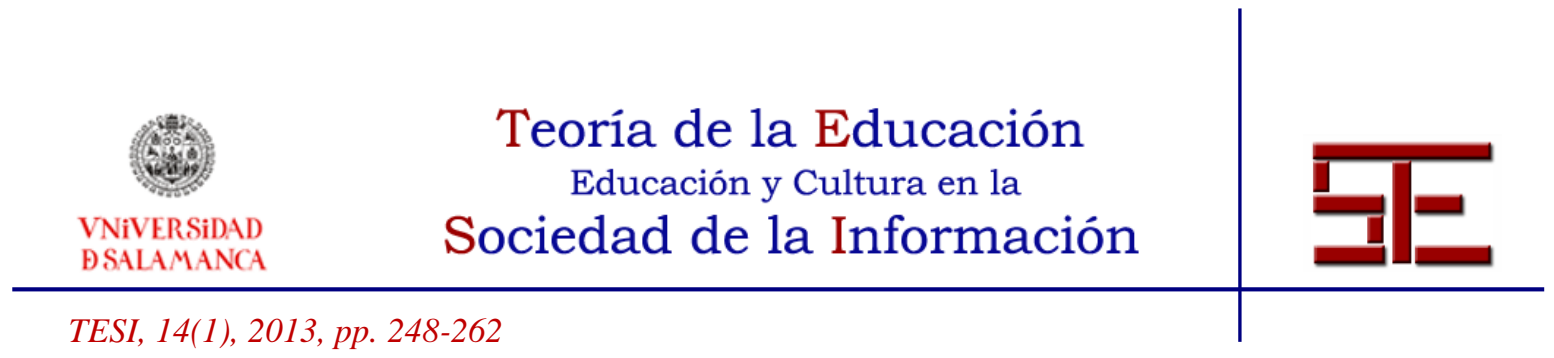

\section{EL LUGAR DE LA AUTONOMÍA EN LA PEDAGOGÍA Y LA EDUCACIÓN POSTMODERNAS}

Fecha de recepción: 10/07/2012; fecha de aceptación: 21/12/2012; fecha de publicación: 28/02/2013

Xavier Laudo Castillo

xlaudo@ub.edu

Universidad de Barcelona

Enric Prats Gil

enricprats@ub.edu

Universidad de Barcelona

\section{INTRODUCCIÓN}

Si la modernidad descubre al yo, para luego casi anularlo en una masa informe, la postmodernidad intentará recuperarlo desde el hallazgo de la alteridad, de la heteronomía. Éste es el argumento central de esta comunicación, que intenta ligar algunos elementos para reflexionar pedagógicamente sobre la autonomía y la responsabilidad desde posiciones a caballo de unos tiempos marcados, doblemente, por una modernidad tardía y una suerte de postmodernidad precoz. Se trataría, usando la expresión de Mèlich y Bárcena (1999), de heteronomizar la autonomía, o, en otras palabras, de secularizar al sujeto, elevado a categoría de sagrado desde la modernidad.

Como se ha dicho sobradamente, la postmodernidad ha embestido los fundamentos de la modernidad con las mismas herramientas conceptuales de ésta. Como indicaba Connors ya en 1989, «es sorprendente el grado de consenso al que se ha llegado en el discurso postmoderno sobre la inexistencia de posibilidad alguna de consenso, los pronunciamientos autoritarios sobre la desaparición de la autoridad última y la promoción y circulación de una narración total que comprende una condición cultural donde la totalidad ya no es posible» (Connors, 1989: 14). Lo que, un tanto demagógicamente, a juicio de este historiador del arte resultaba paradójico, era que la insistencia de las posiciones postmodernas en la «irreductibilidad de diferencias», que impediría incluso la crítica cultural, estaba cayendo en sus mismas trampas, adoptando el lenguaje conceptual de la modernidad. Las herramientas de análisis de una supuesta condición postmoderna tienen una raíz indiscutiblemente moderna, como no puede ser de otro modo. La crítica se realiza siempre por un procedimiento racional y con el utillaje conceptual disponible. Esta comunicación intentará alejarse del entramado supuestamente embaucador que ha

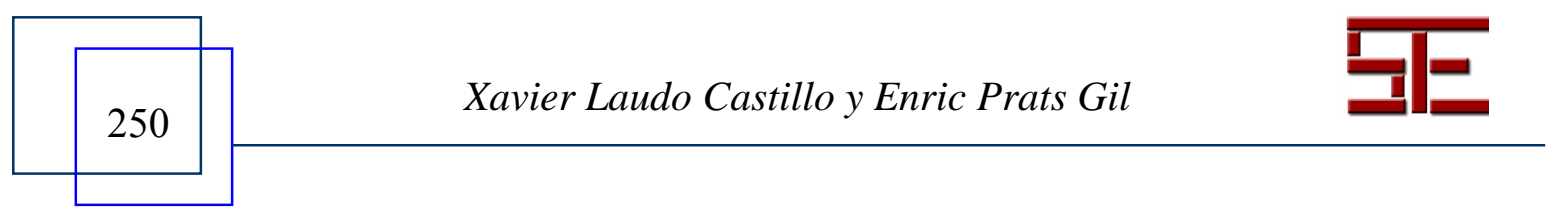




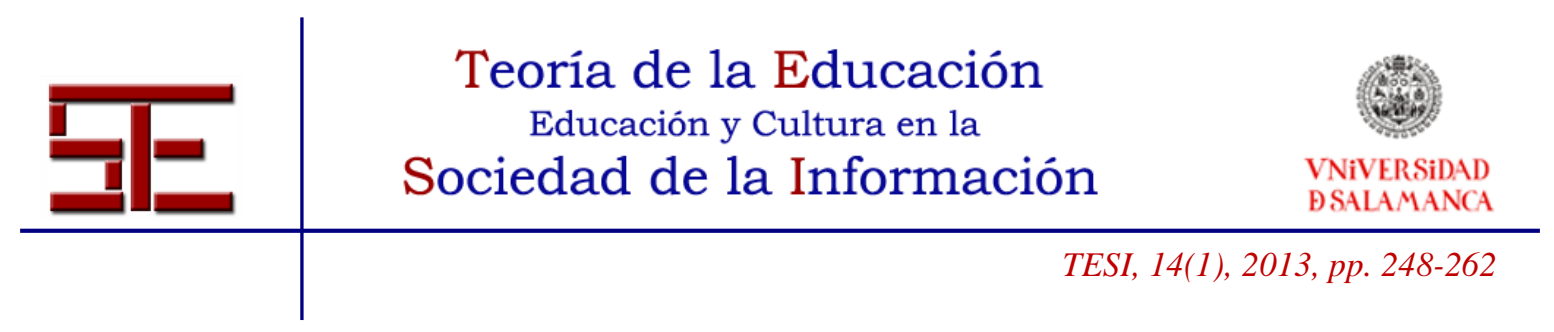

acompañado mucha de la producción denominada postmoderna, pero no puede esconder la dificultad de replantearse categorías muy enraizadas en nuestro pensamiento moderno. Lo cual no elimina, sino que refuerza, la alerta central de la postmodernidad: que los presupuestos de verdad sobre los que habíamos construido nuestras certezas se tambalean, y que está en discusión si todavía siguen en pie.

\section{POSTMODERNIDAD EPISTEMOLÓGICA, LIQUIDEZ SOCIOLÓGICA}

\subsection{La crítica postmoderna}

Como es conocido, los grandes vectores y relatos a través de los que se vertebra la modernidad quedarían enmarcados en este cuadrado: la creencia en un horizonte de progreso y perfección del futuro; la identificación del triunfo de la razón con la linealidad y la meta de la historia; la educación de la sociedad como una misión de la élite cultural para lograr la emancipación individual y colectiva; y una visión representacional del mundo según la cual hay una realidad objetiva a la que puede accederse mediante la aplicación de un método (Vattimo, 1990; Terrén, 1997). En referencia a lo dicho, la postmodernidad, según la definición ya canónica de Lyotard, sería la crisis basada en la incredulidad respecto a los grandes relatos como legitimadores del saber (Lyotard, 1994, 9-10), se trate bien de un relato de emancipación de la humanidad bien de uno acerca de la especulación y el conocimiento científico de la realidad (Lyotard, 1994, 63, 73). Fue el mismo Lyotard quien refirió la sociedad postmoderna en los términos siguientes: «Las sociedades denominadas modernas fundan sus discursos de verdad y justicia sobre grandes relatos históricos y también científicos, unos y otros se colocan en la línea de una impresionante odisea progresista. Pues bien: en las sociedades postmodernas, en las cuales vivimos, lo que no se encuentra es precisamente legitimación de lo verdadero y lo justo... Ya nadie cree en salvaciones globales» (Lyotard y Descamps, 1984, 151-152).

Un punto fundamental del proyecto moderno es la aspiración a lo que Panikkar (2007) llamó «el mito» del conocimiento objetivo de la realidad, y es que no hay duda de que el debate posmoderno gira en torno a la realidad, o irrealidad, o multiplicidad de realidades (Lyon, 1994, 23). El conocimiento en la modernidad se concibe en permanente cambio. Un cambio que, a su vez, se entiende como mecanismo de ajuste progresivo a la realidad. De modo que, aunque las teorías se reconozcan esquemas conceptuales aproximativos, predominará la creencia de que «el conocimiento siempre es como movimiento de aproximación gradual a la verdad absoluta» (Cabrera, 2005, 47). En cambio, se podría decir que lo postmoderno denosta la perspectiva criptokantiana que ha dominado la cultura moderna en la que hay una cosa en sí que es el mundo, aunque se puedan tener

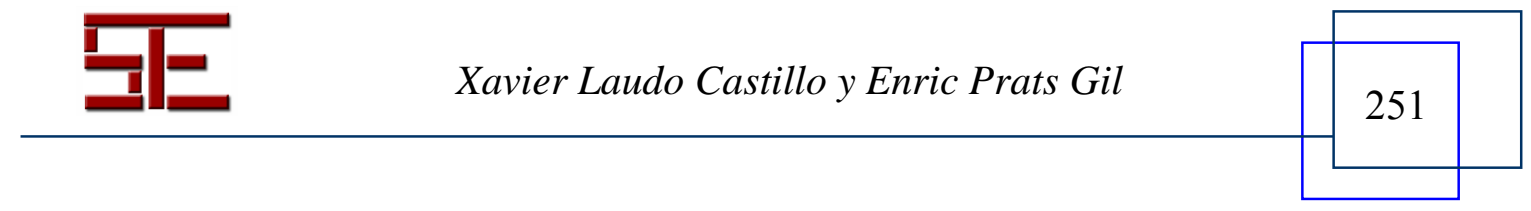




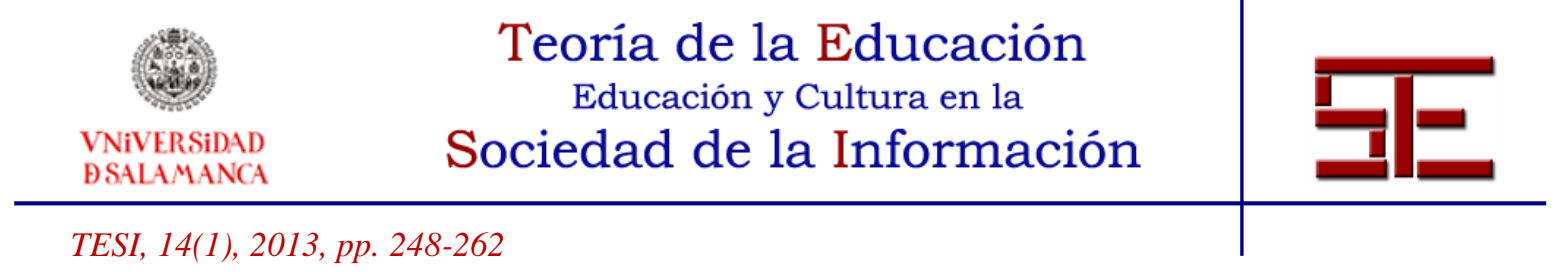

visiones diferentes del mismo. Parafraseando a Panikkar, la postmodernidad podría entenderse como una kosmología, en el sentido que

Kosmología con $k$ no es la visión del mundo según el logos, no es como yo veo el mundo, sino más bien como el mundo me ve a mí, como yo vivo en el universo. Por lo tanto, si tomamos seriamente la interculturalidad, no es que los indios, los aztecas, los mayas tuvieran otra concepción del mundo -de nuestro mundo, naturalmente, el que ha comenzado con el Big Bang y que terminará no se sabe cómo-, es que viven en otro mundo. No es una diversa concepción del universo, es un universo diferente (Panikkar, 1999, 31-31). Se postula, pues, en ese sentido, la no existencia de una única realidad ni de un único conocimiento verdadero, y eso sin negar la realidad ni el conocimiento. Lo que la crítica postmoderna hace ahora es «distinguir entre realidad y objetividad, entre los hechos realmente existentes y la forma en que son captados y explicados» (Cabrera, 2005, 39). Es decir, pone en cuestión la accesibilidad a la verdad, entendida de forma objetivamente absoluta. De ahí que se considere que ese tipo de aspiraciones son características de la modernidad y configuran al sujeto moderno como «un heredero de la ansiedad cartesiana, alguien que no puede aceptar la ambigüedad, la falta de claridad y certeza, ni la diversidad de opiniones a menos que concluyan en un acuerdo racional» (Bárcena, 2005, 56).

\subsection{La liquidez social de la 'condición postmoderna'}

La metáfora líquida, ensayada y popularizada por Bauman, hace referencia a la cada vez mayor imposibilidad de fijar ni mantener rígidos los espacios y los tiempos en los que se desarrollan las actividades humanas (Bauman, 2000, 2). «Líquido» es aquel material que sufre un continuo cambio de forma cuando es sometido a tensión, por eso la metáfora es adecuada y nos sirve para expresar lo constante de los cambios y lo frágil de los vínculos en nuestra sociedad. La «sociedad moderna líquida» es aquella en la que «las condiciones sobre las que sus miembros actúan cambian más rápido de lo que tardan en consolidarse en hábitos y rutinas» (Bauman, 2005ª, 1$)$.

La vida líquida se ha caracterizado como una continua «sucesión de nuevos comienzos», sea cual sea el aspecto de la vida cotidiana del que hablemos; ya sean vidas laborales o sentimentales. Aunque, por encima de todo, se destaca la dificultad para «cerrar o terminar» los distintos episodios de la vida de cada uno. Es en este sentido que Bauman matiza y reformula la primera expresión hasta dejarla en una "sucesión de finales», poniendo el acento en la cara más esquiva de la moneda, la habilidad más difícil y que requiere más entrenamiento. Según esta descripción las identidades que nos definen y con que nos presentamos se adoptan y se abandonan rápidamente.

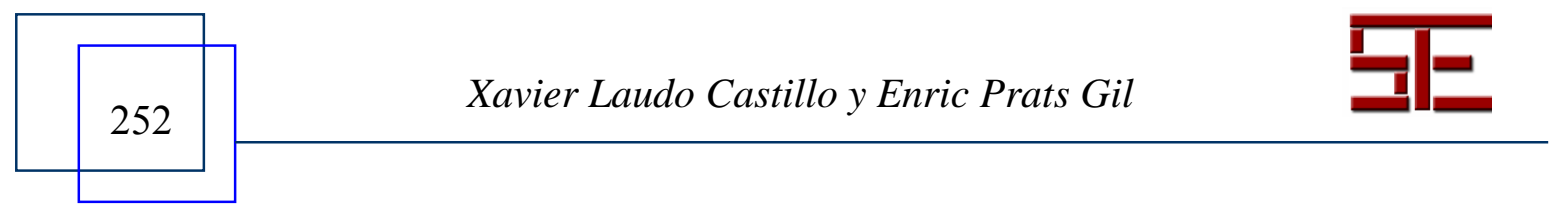




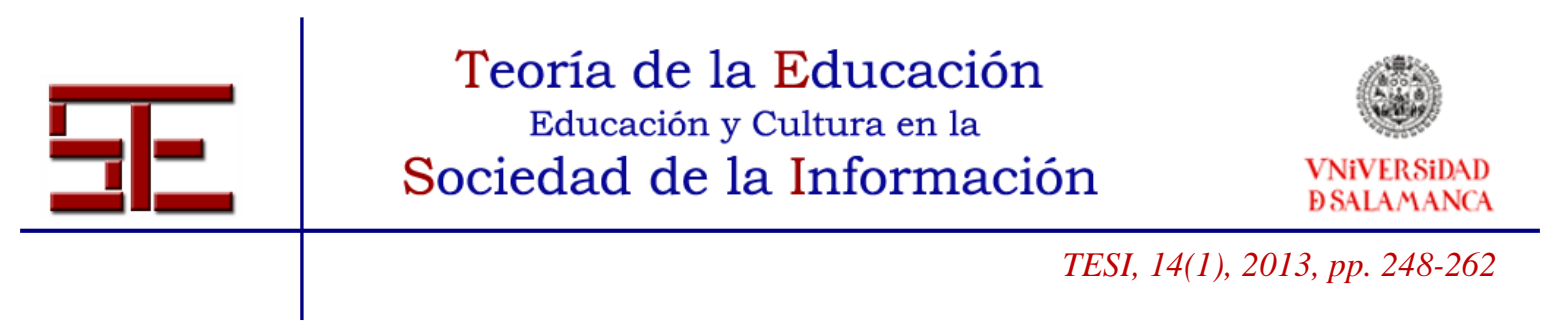

Si hablamos de valores, «importa la velocidad, no la duración». Se perfila un «arte de la vida líquida» cuyas características son: «aceptación de la desorientación, inmunidad al vértigo, tolerancia a la ausencia de itinerario y dirección, e indefinida duración del viaje» (Bauman, 2005a 4). Es como decir que para sobrevivir en la sociedad moderna líquida se impone cada vez más el sentirse cómodo sin saber a dónde se va; desarrollar la costumbre de pasar por los lugares y las experiencias a gran velocidad y sin tomar compromisos; saber prescindir de un mapa de ruta, incluso de señales y de brújula, y, a la postre, reconocer que de todo lo dicho no se sabe hasta cuándo. Bauman lo ha expresado de otro modo, aunque insistiendo en la misma idea, proclamando que en nuestro mundo moderno líquido el arte de la vida es hacer de la vida una obra de arte, mantenerse en un estado de transformación permanente y redefinirse perpetuamente convirtiéndose en alguien diferente del que se ha sido hasta el momento (Bauman, 2009).

Del mismo modo, la idea de postmodernidad de Bauman se resume como la condición bajo la cual entendemos que tenemos que modificar nuestras estrategias de vida de acuerdo a la idea de que la modernidad no es sólo un proyecto inacabado (aunque quizá tampoco agotado), sino que se trata de un proyecto inacabable. Para el pensador polaco, «la modernidad siempre fue un proceso de fundir lo sólido» (Beilharz, 2001, 421) y de cambio constante, quitar una cosa para poner otra, sólo que con una dirección y una finalidad concretas. La ausencia de éstas es lo que marca la diferencia con la postmodernidad. Pero la idea es que, siguiendo con la metáfora, la modernidad no pretendía acabar para siempre con y liberarse de los sólidos, sino sustituirlos por otros sólidos mejores (Bauman, 2000, 4). Ocurre que, en este momento, la fundición se ha completado y no sabemos qué vendrá después. Esa sociología nos conmina a pensar en clave líquida. Ello a pesar de que, en palabras de Connor, «el conocimiento siempre está condenado a llegar demasiado tarde a la escena de la experiencia» $(1989,9)$, y sólo podemos captar aquello que nuestras capacidades de cognición y de representación condicionadas por nuestro tiempo nos permiten. A lo sumo, el arte estaría en condiciones de recoger esa realidad, pero no así la ciencia social.

\section{AUTONOMÍA Y POSTMODERNIDAD, EN CLAVE PEDAGÓGICA}

A efectos publicitarios, parecería que autonomía y modernidad aparentemente son expresiones que forman parte del mismo eslogan. Pero como denota una de las expresiones con las que Bauman ha tratado de arrojar luz sobre nuestra sociedad («Melting Modernity»), en esta modernidad de nuevo cuño, los fundamentos que la

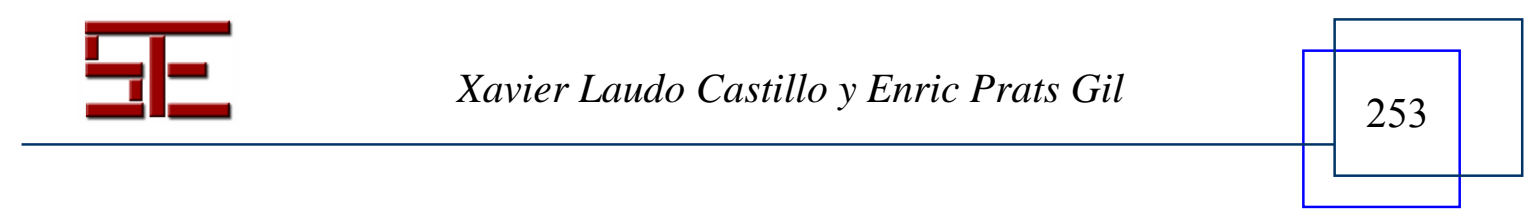




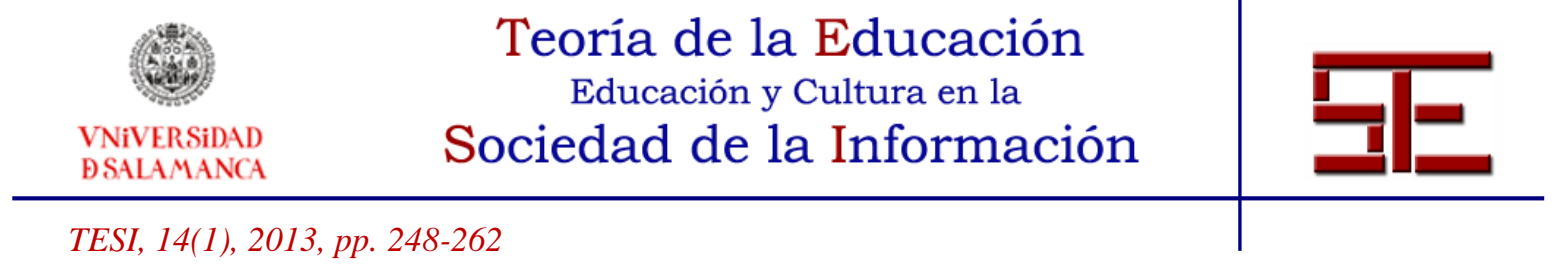

sustentaban empezarían a perder fuelle, a fundirse en un nuevo emplazamiento por reedificar. La modernidad parece fundirse. ¿También su imperativo de autonomía?

Para Adela Cortina la autonomía vendrá a ser como la versión tardomodernizada del individualismo (Cortina, 1990, 279 y ss.; la expresión tardomodernizada es nuestra), de la misma manera que el colectivismo de la primera modernidad cederá el paso a la solidaridad. En cualquier caso, libertad e igualdad, regulados por el principio de justicia, serán pilares básicos sobre los que se construirá el edificio de la modernidad. Por supuesto, el sujeto se sitúa en el centro de toda esta argumentación. En la modernidad se sacraliza al sujeto, mientras que en la postmodernidad se intentará secularizarlo, quizá para evitar la triste caída de esa nueva divinidad.

Su secuencia histórica podría describirse como sigue. La modernidad es el proceso de mundanización de la razón: la atribución universal de capacidad creadora al ser humano. La razón es la herramienta mediante la cual el ser humano ejerce su capacidad creadora, para intentar superar la barbarie. La ciencia ejecuta los planes de la razón humana. Mundanizando la razón, la modernidad extiende esa atribución a toda la especie humana, responsabilizándola de sus actos. Los derechos humanos certifican esos atributos. En esta atribución universal (o universalizadora), el ser humano adquiere, por su condición biológica (más que cultural), un grado indefinido e infinito de intervención y transformación sobre el medio. Esa nivelación casi divina prepara el terreno a la postmodernidad.

Muchos han sido los autores que, basándose en este aserto, han demonizado a la razón. Y no les han faltado argumentos, ya que el ser humano, que con la modernidad adquiere la condición de ciudadano sin haberlo solicitado, encuentra en la razón un horizonte con un alto potencial creativo, sin más límite que el que le impone su imaginación (el arte, en clave postmoderna, colaborará a ampliar esos márgenes). El requisito que se impone aquí es la autonomía. La autonomía rompe el monopolio de la divinidad, que vendrá a ser sustituida por la civilidad, alcanzable si se aplica la razón al bien común. Para Mark Taylor, cuando el «apocalipsis mediante la revolución dejó paso al apocalipsis mediante la imaginación y el conocimiento, la conciencia se volvió hacia dentro y se hizo autoconciencia. Sin embargo, empujándose a sí misma hasta su límite, la autoconciencia autónoma se hizo an-árquica. Es decir, el sujeto descubre que ha surgido un fundamento infundamentado [la an-arquía, (sic)] que nunca puede alcanzar. Esta fisura crea la apertura para la crítica postmoderna del modernismo» (Taylor, 2011, 139).

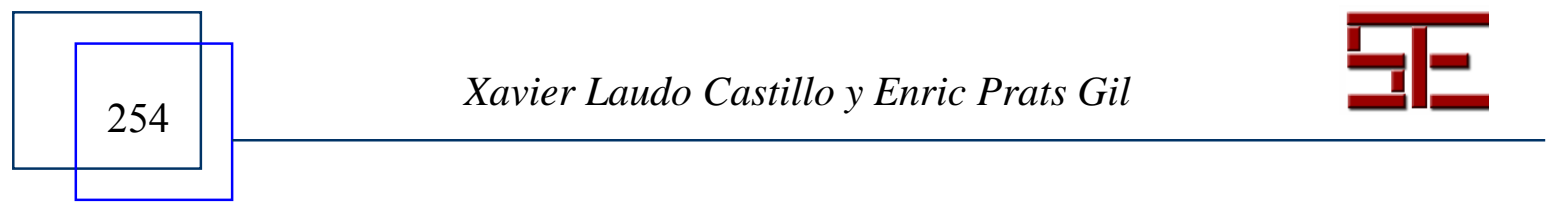




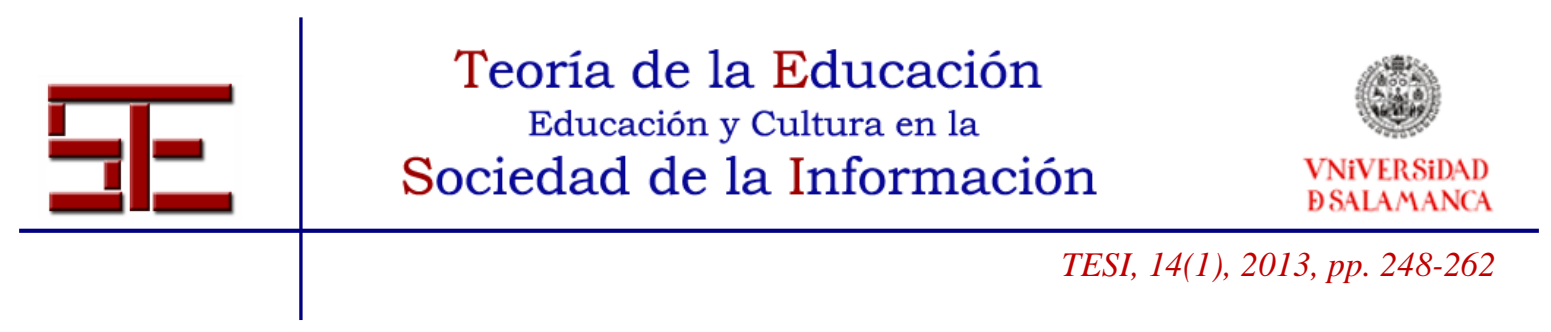

Si postmodernidad significa la «no aceptación de la existencia de realidad alguna que se presente como absoluta, autónoma y suficiente» (Fullat, 2002, 341), una vez instalada la crítica a esos fundamentos, se sigue de ellos que «la relación pedagógica ya no puede ampararse en las metanarrativas y universales característicos de la cultura pedagógica de la modernidad» (Terrén, 1997, 121). Tiene sentido, pues, que la pedagogía, en tiempos de postmodernidad, dada la importancia y la sustancialidad de los cambios ya presentados, deba replantearse sus presupuestos y principios.

Se ha advertido del peligro de las utopías propositivas y se ha resuelto que lo que la educación debería hacer no es tanto implementar o realizar proyectos y programas sino mantener permanentemente abiertos espacios y tiempos donde otros significados puedan ser pensados y articulados (Masschelein, 1998, 529-530). Incluso se ha llegado a afirmar que «los objetivos emancipadores de la Modernidad se han mostrado inútiles y hasta perniciosos. No existe un sentido único de la historia sino múltiples. El sujeto transformador de la sociedad tiene que desaparecer si queremos librarnos de los dictadores» (Fullat, 2002, 371).

Instalado en la postmodernidad, un pedagogo podrá defender y luchar por promover cualesquiera proyectos educativos, pero según Carr, al conceder que no hay nada exterior a la experiencia, ni "esencia" de la naturaleza humana ni "destino" hacia el que inevitablemente se dirija la historia, también se concede que el único modo de justificarse consiste en apelar a su fe en la disposición de los profesionales corrientes de la educación a reconstruir su práctica de manera que exprese los valores e ideales educativos emancipadores (Carr, 1995a, 164). Tal vez este cambio de pivote, de una razón compartida a un acto de fe, podría explicar algunas de las reivindicaciones neoconservadoras actuales en materia educativa, tanto las que defienden la separación de sexos, para favorecer el aprendizaje, como la supuesta base genética de las diferencias de resultados, como acaba de aportar un reciente estudio de la Comisión de Educación de la patronal española $\mathrm{CEOE}^{1}$.

Esto dificulta la tarea de teorizar y de hacer pedagogía en clave postmoderna. Por ejemplo: la solución habermasiana del «consenso alcanzado de acuerdo a principios correctos de argumentación» ha sido tildada de «fundacionalismo débil», dado que en ella el procedimiento de reglas de argumentación racional hacía las funciones de un principio primero, igual que los religiosos o políticos al uso (Van Goor; Heyting; Vreeke, 2004,

${ }^{1}$ Véase El País, 22 de junio de 2011: «La CEOE ve en los genes la clave del éxito escolar».

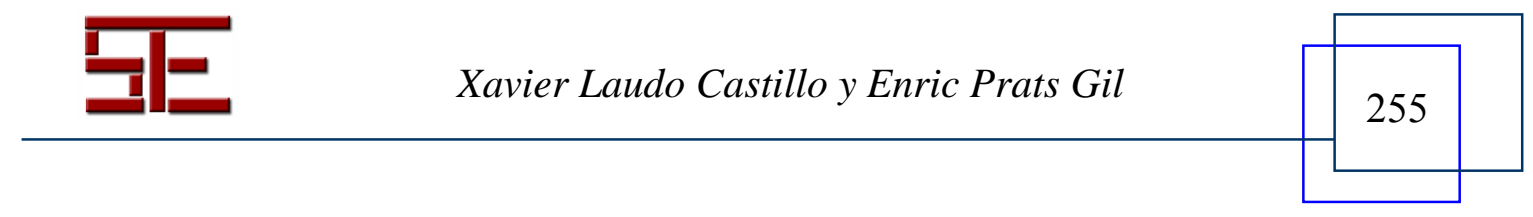




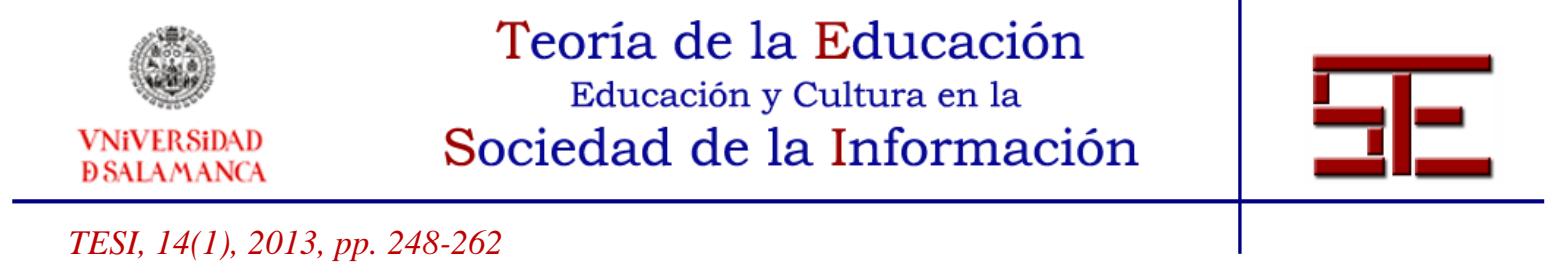

176-191). Y es que, pese a «las tentativas por ver en este discurso de la posmodernidad la continuación de un enfoque crítico e incluso tecnológico, lo cierto es que el mismo supone una ruptura que sitúa la discusión sobre las posibilidades del conocimiento pedagógico en un plano radicalmente diferente» (Bárcena, 2005, 38).

Tal y como dijo Parker en su Manifesto for education in postmodernity, para los educadores postmodernos una teoría general es precisamente algo que ya no puede ser escrito, con lo que no queda otra solución que remitirse a relatos sobre tal o cual situación y a pensar y discutir en cada lugar y momento los juicios y acciones que se puedan proponer. Cada decisión del educador no podrá estar fundamentada en una realidad ni en una justificación última (Parker, 1997, 142-144). Esto incluye el obedecer una máxima, como en el paradigma ético kantiano. En los últimos años, Carr ya se ha referido al pensamiento educativo postmoderno en términos de postfundacionalismo. Con esto, señala de qué manera el discurso filosófico actualmente vigente reconoce que los cambios irreversibles en las formas como entendemos y nos relacionamos con las ideas y creencias de la modernidad han sido tan profundos que las formas de teorizar que continúan basándose en asunciones fundacionalistas ya no son aceptables si intentamos hacernos cargo del mundo contemporáneo (Carr, 2006, 150). El imperativo categórico kantiano, paradigma de las éticas deontológicas en cualquiera de sus formulaciones, no dejaría de ser una suerte de fundamento al que someter jerárquicamente la conducta. Puestas así las cosas, ¿no podría entenderse esa obsesión moderna por la autonomía como un fundacionalismo más que hay que revisar?

\section{LA AUTONOMÍA DESPUÉS DE LA POSTMODERNIDAD}

Como ya puso de relieve la crítica foucaltiana, a través de la autonomía se ha ejercido el control social durante la modernidad, habiendo sido tarea central de la pedagogía moderna. Una pedagogía al servicio de la modernidad que, como afirma Nóvoa, «produce un trabajo laborioso de unificación cultural que se hace a través de criterios científicos (la razón) y de criterios de ciudadanía (la responsabilidad)» (Nóvoa, 2005, 262). Según el autor portugués, «hay un clima conservador, que es, al mismo tiempo, un clima de "fin de ciclo", de una forma histórica que está terminando, sin que, todavía, tengamos claro la forma emergente», que nos obliga a «buscar una nueva pedagogía, sin duda recuperando algunas experiencias y teorías del pasado. Pero esta pedagogía de la contemporaneidad habrá de ser muy diferente de la pedagogía de la Modernidad que ha dominado el siglo XX» (ibid., 266). Una pedagogía postmoderna deberá, quizá, desvelar, impugnar, omitir

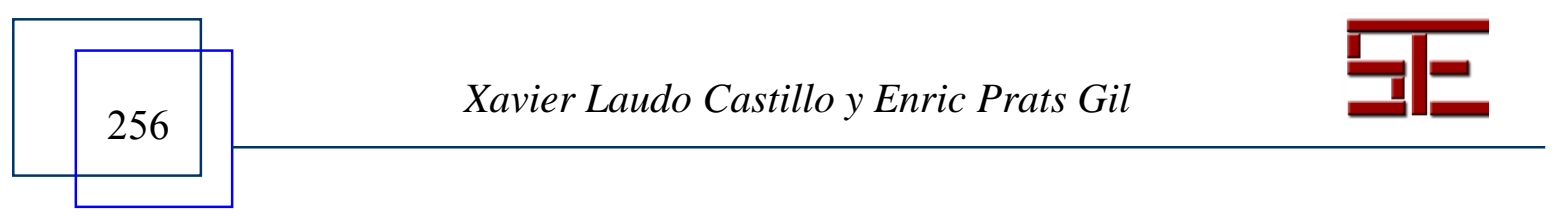




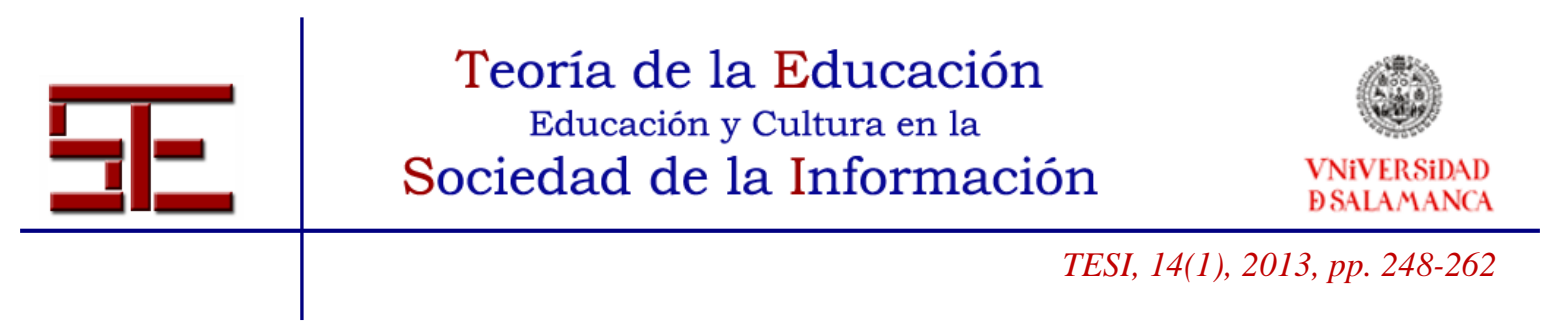

o negar una cierta concepción de la educación: aquella que consiste en que el educando debe -en palabras de Durkheim en el XX-, «aprender a encontrar la palabra del maestro en su consciencia y querer seguirla», y -expresado por Compayré en el XIX-, «preparar la libertad para obtener la obediencia, [...] preparar al niño para que se gobierne a sí mismo, porque ésta es la manera más eficaz de conseguir el orden y la disciplina». Es esto a lo que el profesor Nóvoa se ha referido como «la mejor definición de la imbricación entre los registros de la libertad y del control, de la autonomía y la regulación, que definen la matriz pedagógica del siglo $X X »^{2}$. Desde este enfoque la pedagogía moderna sería aquella donde «las prácticas de libertad y de autonomía llegarán a estar íntimamente conectadas con las prácticas de regulación y de control», y que respondería al siguiente objetivo: que «educar y educarse sean una y la misma cosa» (Nóvoa, 2005, 258-259).

Para Parker, el vocabulario de la enseñanza reflexiva (reflective teaching) siempre ha incluido, hasta ahora, los términos autonomía, libertad y emancipación. Pero, afirma, «ver la autonomía como simplemente la finalidad de la reflexión (reflection), sin embargo, sería infravalorar seriamente su importancia retórica» (Parker, 1997, 122). El concepto de autonomía en la pedagogía moderna ha sido entendido como la ausencia de acciones arbitrarias y la liberación de la distorsión en las condiciones psicológicas originarias para la acción», lo que «implica el pensar y el actuar en fidelidad a algo. Sea lo que sea ese algo -continúa Parker, su rol es establecer las elecciones de la persona como propiamente suyas más que de ningún otro y, más allá, como auténticamente suyas, sinceras y racionalmente concebidas en vez de proceder de ocurrencias arbitrarias. Eso presupone, por supuesto, que las reglas de la racionalidad no están ellas mismas arbitrariamente escritas, que son, en otras palabras, autónomas en su autointegridad. Los estándares a los cuales la persona autónoma es fiel, entonces, deben de algún modo estar necesariamente contenidos en -o constituidos por- su propia peculiar naturaleza pero regulada, vigilada, autorizada, por una racionalidad legislativamente independiente (Parker, 1997, 128).

¿Deberíamos renunciar a la enseñanza reflexiva? Para Parker, aunque considera la autonomía como una ideología más, taxativamente no. Pero para eso hace falta otro relato que reconozca la ironía. Es necesario reconocer que la autonomía es un producto de nuestros valores y que nosotros mismos la hemos situado en un papel protagonista, pero en ningún caso obedece a una razón necesaria de tipo universal. La autonomía puede tener un papel, en el cual nosotros dibujamos una distinción entre la conducta que se ajusta al

${ }^{2}$ Las citas de Durkheim y Compayré pertenecen a sendas entradas del Dictionnaire de Pédagogie et d'Instruction Primaire de Buisson, en las ediciones de 1911 y 1883, respectivamente, que hemos extraído del mismo texto de Nóvoa $(2005,259)$.

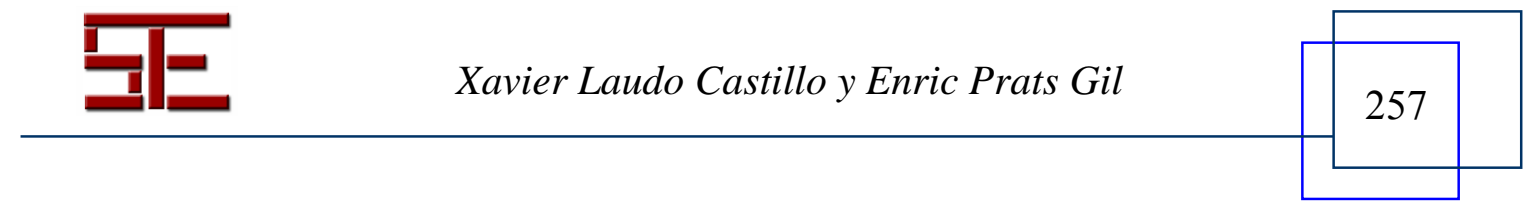




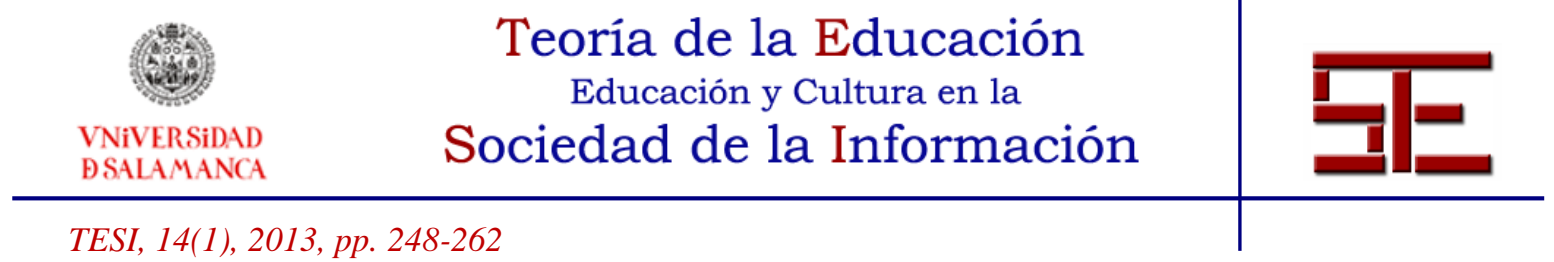

canon y la que no. Pero lo que no se puede es dejar de tener en cuenta el relativismo de la postmodernidad (Parker, 1997, 135). Lo que se está planteando, por tanto, es la necesidad de dar una mirada a la autonomía que no parta del mismo sujeto, sino del que tiene delante, del que le interpela. La alteridad, o la heteronomía como ha sido bautizada para reclamar la necesidad de que las normas surjan de ese proceso dialéctico con el otro, pondrá sobre el tapete la objeción de que la autonomía, por si sola, lleva al colapso. Mélich y Bárcena (1999), como Child y otros (1995), ya habían recogido la alerta, planteada por Levinas, de que, después del horror totalitario, no se podía seguir confiando en la idea kantiana de autonomía, y que era necesario revisar la noción de heteronomía. La responsabilidad, que sería la misma cara de la moneda que la de la autonomía, exige mirar al pasado, «en el recuerdo y en la memoria. Se trata de transmitir, a través de la memoria, una ética de la vigilancia, una actitud y unos medios para que las jóvenes generaciones sean más vigilantes que las mayores» (Mélich y Bárcena, 1999, 478). No es una remembranza de los horrores ni un control social lo que se propone, sino una atenta escucha del otro, de un otro que pasa desapercibido en la historia y que, en determinados momentos altamente críticos, devienen víctimas de la historia.

La responsabilidad, como capacidad responsiva del sujeto, se entiende únicamente en clave comunitaria. Es decir, la autonomía adquiere sentido cuando es sometida al dictado de la responsabilidad, algo que los comunitaristas vienen reclamando desde hace tres décadas. El multiculturalismo ha puesto en evidencia que la lucha intercultural no puede limitarse a un mero reconocimiento de las diferencias históricas, sino que el núcleo duro se encuentra precisamente en la superación de las injusticias motivadas por una concepción eurocéntrica y colonial de la diferencia, lo cual sólo puede pasar por asumir las responsabilidades de los grupos dominantes con el pasado. Así, en palabras del socioconstructivismo moral, después de introducir al educando en los valores básicos de nuestra tradición, haría falta forzar un ejercicio hermenéutico de toma de distancia para relativizar precisamente nuestros valores y pautas morales, y que ese educando se percatase de que estas pautas y normas son particulares de una tradición (la nuestra), de que no son universales, lo que nos llevaría a determinar que el trabajo pedagógico de la autonomía moral no es suficiente.

Por supuesto, esa apuesta por la heteronomía no está exenta de peligros. Precisamente cuando entendemos la responsabilidad como compromiso con lo colectivo, es muy probable que la estricta responsabilidad que me corresponde como individuo quede diluida en la del colectivo, por lo que fácilmente podrá ocurrir que nadie llegue a asumir realmente sus obligaciones. Los límites que impone la comunidad no siempre tienen

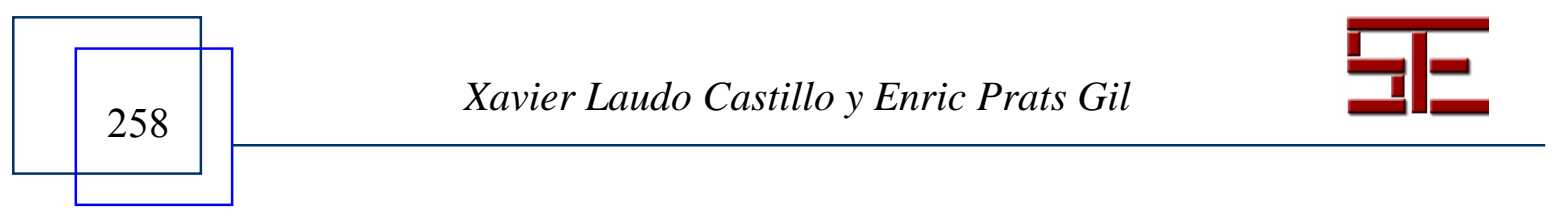




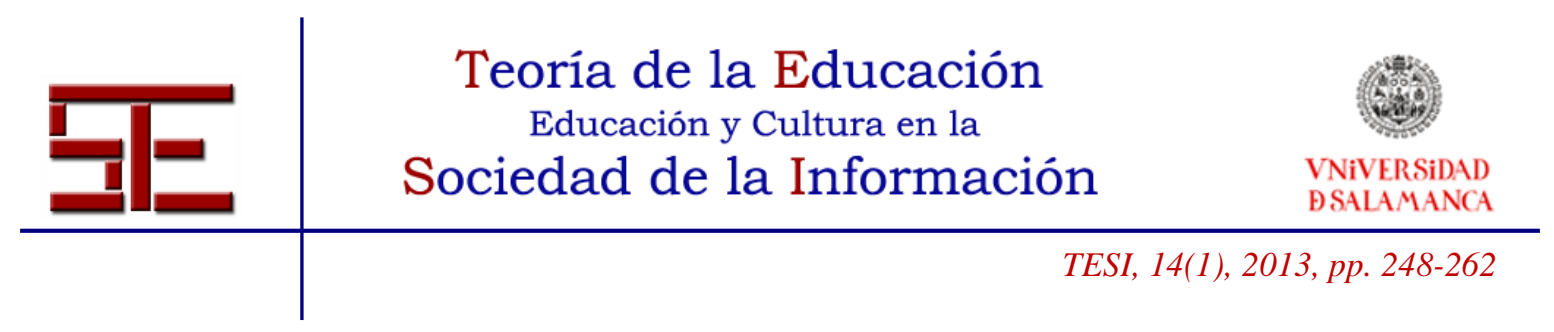

como consecuencia que uno, tomado individualmente, asuma su deber, a no ser que se delimiten particularmente esas obligaciones. En educación, esto puede significar, por ejemplo, que la responsabilidad por alcanzar determinados niveles de rendimiento académico o bien queden circunscritos al grado de esfuerzo y trabajo realizado por cada estudiante, por lo que el éxito o el fracaso se medirá en base a su resultado final, o bien queden supeditados a las condiciones estructurales y coyunturales que explican ese resultado, por lo que el responsable último será el sistema tomado de manera anónima o, peor aún, como entelequia amorfa.

Puestas así las cosas, después de la postmodernidad, la autonomía se abandona en autenticidad, argumento central de los comunitaristas: «Mientras que la autonomía definiría dimensión moral en términos más estrictos, universalistas y legaliformes, la autenticidad incorporaría al reino moral un interés específico en la particularidad y el contexto, de la mano, por ejemplo, del juicio y la expresión estéticas» (Thiebaut, 1998, $84)$. Como puso de relieve Bauman (2003, 85 y ss.), en la comunidad estética los vínculos son friables y efímeros, bien al contrario que en la comunidad ética, que se organiza mediante compromisos a largo plazo, con derechos inalienables y obligaciones irrenunciables: lo que se busca en la comunidad es una garantía y seguridad de permanencia, algo que puede conceder la comunidad ética basada en la autonomía, pero no tanto la comunidad estética centrada en la autenticidad. La comunidad ética exige una adscripción en un contexto de relaciones sólidas; la comunidad estética lanza proclamas en forma de anclajes para sus adeptos, consciente de la fluidez de sus compromisos, unos anclajes que se adivinan provisionales. Todo lo cual, al parecer de Bauman (2005b), no sería más que una versión renovada, con aires añejos, de la distinción entre societas y comunitas, o en términos más clásicos, entre Gesselschaft y Gemeinschaft.

En este terreno, la educación se ve forzada a reconvertir sus presupuestos y sus acciones. La comunidad educativa viene a ser llamada hacia un proyecto educativo, sin límite de tiempo y espacio, que apuesta por reinventarse en cada esquina. La educación no pretende enseñar nada a nadie; siguiendo a Rancière, la lógica de la emancipación, que no de la autonomización, consiste en asumir que «la ignorancia no es un saber menor, sino que es el opuesto del saber; porque el saber no es un conjunto de conocimientos, sino una posición» (Rancière, 2010, 16). La educación debe tratar de desvelar, de levantar el velo que oculta el entramado de posiciones y el juego de poderes de cada uno de los participantes. En otros términos, como recuerda Aramayo, «querer no es poder»: «Dentro del ámbito de la responsabilidad el querer no basta y tiene que verse necesariamente acompañado por el poder. Para responsabilizarnos de algo se requiere una capacidad

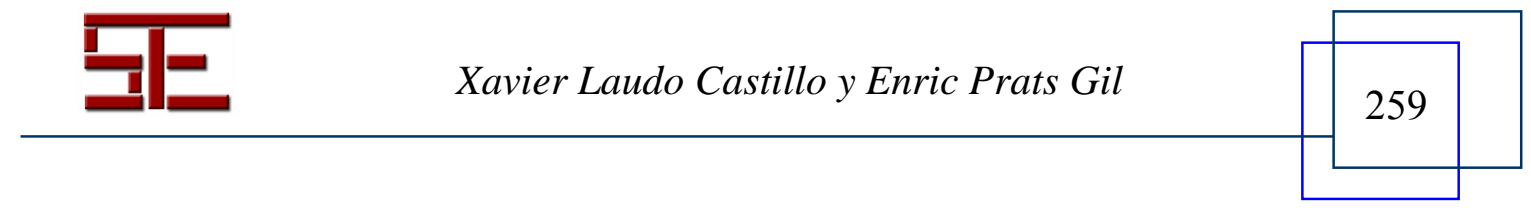




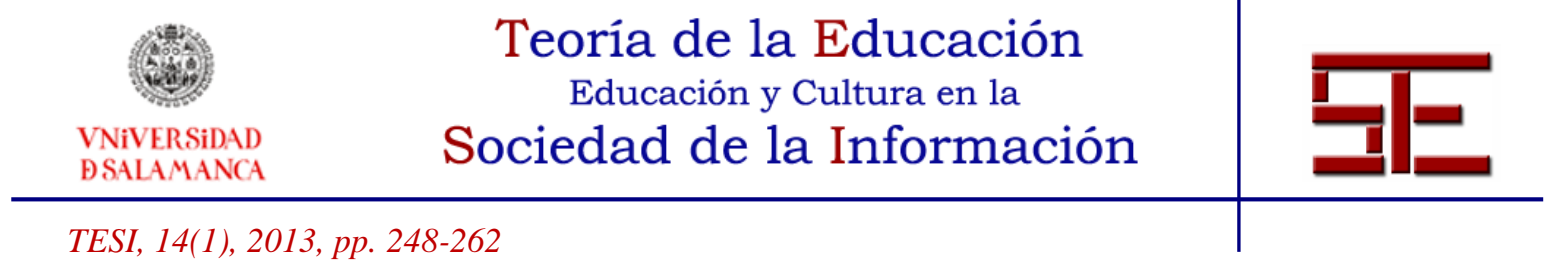

potencial para llevarlo a cabo u obstaculizarlo» (Aramayo, 1999, 30-31). No es (o no se siente) responsable quien quiere, sino quien puede. Y el mismo aserto podría aplicarse a la autonomía en tanto objetivo educativo.

Sea como fuere, es probable que con la pedagogía postmoderna nos encontremos ante un planteamiento pedagógico irreductible a cualquier otra cosa anterior, no ya cronológicamente sino incluso desde un punto de vista lógico y conceptual (Laudo, 2011). Es decir, que hagamos lo que hagamos no podemos escapar del tiempo, de un contexto que podemos aceptar o combatir pero asumiéndolo de algún modo como propio. Así las cosas, para quienes consideren como válida, siquiera en parte, la crítica postmoderna, se plantea el reto de revisar la moderna concepción de autonomía y pensar proyectos educativos desde la heteronomía, desde el reconocimiento de la responsabilidad hacia el otro; proyectos capaces de subvertir los límites ciertamente rígidos apuntalados por la modernidad que habían encumbrado, quizá en demasía, a la autonomía del sujeto como objetivos primero y último de la educación.

\section{4.- BIBLIOGRAFÍA}

Aramayo, R. (1999). Los confines éticos de la responsabilidad. En M. Cruz \& R. Aramayo (coords.). El reparto de la acción. Ensayos en torno a la responsabilidad. Madrid. Trotta.

Bauman, Z. (2000). Liquid modernity. Oxford. Polity Press.

- (2001). Comunidad. En busca de seguridad en un mundo hostil. Madrid, Siglo XXI.

- (2005a). Liquid Life. Cambridge: Polity Press.

- (2005b). Ética postmoderna. Madrid: Siglo XXI, (original de 1993).

- (2009). El arte de la vida. Barcelona: Paidós.

Bárcena, F. (2005). La experiencia reflexiva en educación. Barcelona: Paidós.

Beilharz, P. (ed.) (2001). The Bauman Reader. Oxford: Blackwell.

- (2001). Liquid Modernity, by Zygmunt Bauman. Contemporary Sociology, 30 (4).

Best, S. (1998). Zygmunt Bauman: Personal reflections within the Mainstream of Modernity». The British Journal of Sociology, 49 (2), 312.

Cabrera, M. Á. (2005). La crisis de la modernidad y la renovación de los estudios históricos. En M. Ferraz (Ed.), Repensar la historia de la educación. Madrid: Biblioteca Nueva.

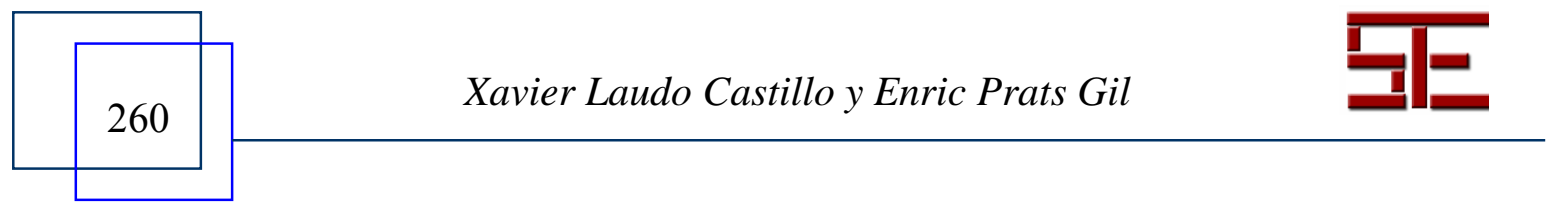




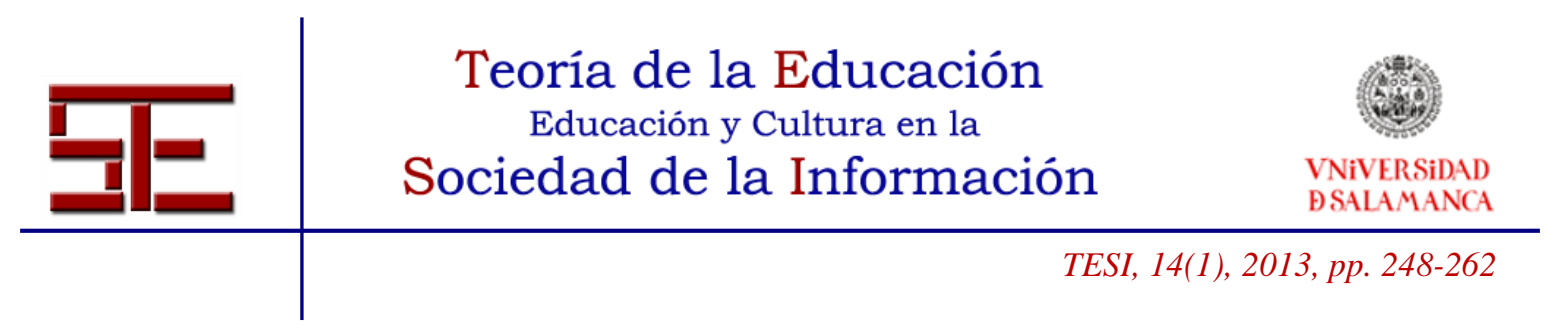

Carr, W. (1995a). Educación y democracia: ante el desafío postmoderno. En Volver a pensar la educación. Política, sociedad y educación (vol. I). [Congreso Internacional de Didáctica celebrado en 1993]. Madrid. Morata.

- (1995b). Una teoría para la educación. Hacia una investigación educativa crítica. Madrid: Morata.

— (2006). Education without theory. British Journal of Educational Studies, 54 (2), 136159.

Child, M., Williams, D., Birch, A. y Boody, R. (1995). Autonomy or Heteronomy? Levinas's Challenge to Modernism and Postmodernism. Educational Theory, 45 (2), $167-$ 189.

Connor, S. (1989). Cultura postmoderna. Introducción a las teorías de la contemporaneidad. Madrid, Akal, 1996.

Cortina, A. (1990). Ética sin moral. Madrid: Tecnos.

Fullat, O. (2002). Pedagogía existencialista y postmoderna. Madrid: Síntesis.

Gil, F. (2008). Ciudadanía y humanidad. La educación en el disenso. Teoría de la educación. Revista Interuniversitaria, 20, 25-44.

Laudo, X. (2006). Pedagogies de la liquiditat. Temps d'Educació, 36, 323-335.

- (2011). La hipótesis de la pedagogía postmoderna. Educación, verdad y relativismo. Teoría de la Educación, Revista Interuniversitaria, 23 (2), 45-68.

Lyon, D. (1994). Postmodernidad: la historia de una idea». En Postmodernidad. Madrid: Alianza.

Lyotard, J. F. (1994). La condición postmoderna. Madrid: Cátedra.

Lyotard, J. F. y Descamps, C. (1984). Jean-François Lyotard dans la société postmoderne. Le Monde, 14/15 de octubre de 1979. En Entretiens avec «Le Monde», Vol. 1, Philosophes. París: La Dècouverte/Le Monde, 149-157.

Masschelein, J. (1998). How to Imagine Something Exterior to the System: Critical Education as Problematization. Educational Theory, 48 (4), 521-530.

Mélich, J. C. y Bárcena, F. (1999). La palabra del otro. Una crítica al principio de autonomía en educación. Revista Española de Pedagogía, LVII, 214, pp. 465-484.

Nóvoa, A. (2005). Razón y responsabilidad: La pedagogía como ciencia del gobierno de almas. En J. Ruiz Berrio (Ed.) Pedagogía y educación ante el siglo XXI. Madrid: Departamento de Teoría e Historia de la Educación de la Universidad Complutense de Madrid.

Panikkar, R. (1999). El espíritu de la política. Barcelona: Península.

- (2007). Mito, fe y hermenéutica. Barcelona: Herder.

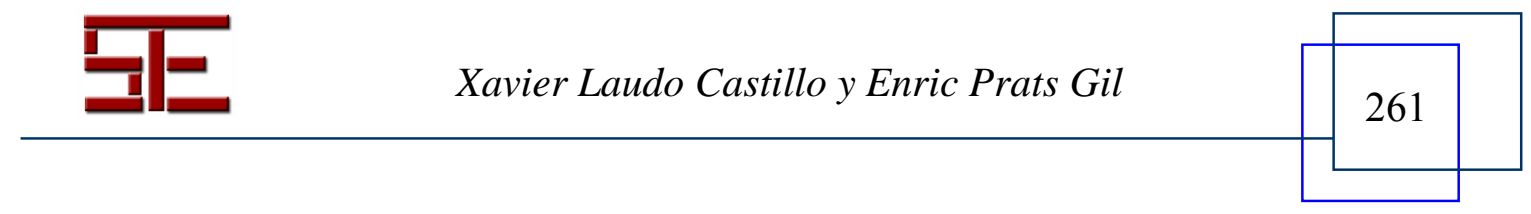




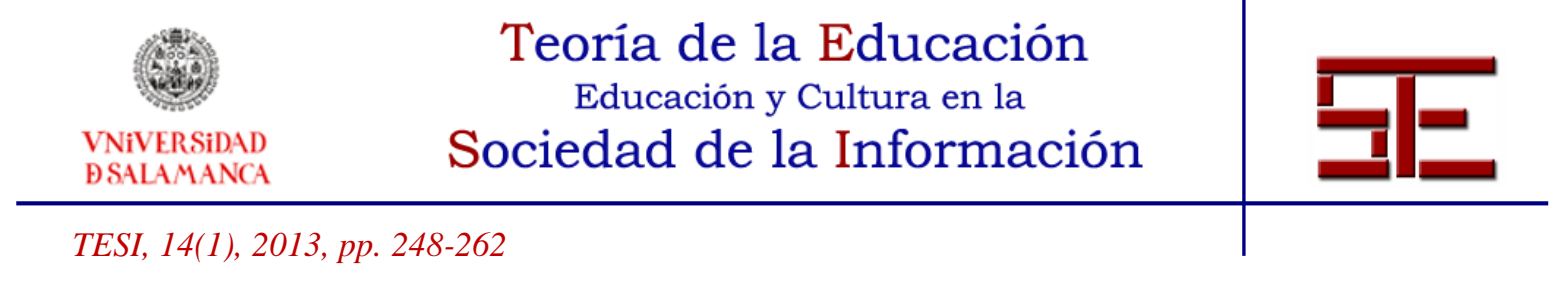

Parker, S. (1997). Reflective teaching in the postmodern world. A manifesto for education in postmodernity. Buckingham: Open University Press.

Prats, E. (2005). Pedagogia líquida per a una educació sòlida: a propòsit de Bauman. Temps d'Educació, 28.

Rancière, J. (2010). El espectador emancipado. Castellón: Ellago Ediciones.

Taylor, M. C. (2011). Después de Dios. La religión y las redes de la ciencia, el arte, las finanzas y la política. Madrid: Siruela. (Trabajo original publicado en 2007).

Terrén, E. (1997). Postmodernidad y educación. Política y sociedad, 24.

Thiebaut, C. (1998). Vindicación del ciudadano. Un sujeto reflexivo en una sociedad compleja. Barcelona: Paidós.

Van Goor, R., Heyting, F. y Vreeke, G-J. (2004). Beyond Fundations: Signs of a New Normativity in Philosophy of Education. Educational Theory, 54 (2), 173-192.

Vattimo, G. et al. (1990). En torno a la postmodernidad. Barcelona: Anthropos.

Para citar el presente artículo puede utilizar la siguiente referencia:

Laudo Castillo, X. y Prats Gil, E. (2013). El lugar de la autonomía en la pedagogía y la educación postmodernas. Revista Teoría de la Educación: Educación y Cultura en la Sociedad de la Información. 14(1), 248-262 [Fecha de consulta: dd/mm/aaaa].

http://campus.usal.es/ revistas_trabajo/index.php/revistatesi/article/view/9451/9740 